\title{
ARTICLE
}

\section{Temporal Change in Spatial Patterns of a Series of Heavy Rain Indicated by Spatial Variograms}

\author{
Tetsuya SHOJI \\ University Museum, The University of Tokyo, Tokyo 113-8583, Japan \\ E-mail address: t-t_shoji@jcom.home.ne.jp
}

(Received: 3 August 2010; Accepted: 24 September 2010)

\begin{abstract}
Japan from noon on the 13th to midnight on the 14th, August 1999 (36 h) have been analyzed in order to find a method indicating any temporal change in spatial rainfall patterns of a series of heavy rain. The analysis is mainly based on correlation coefficient and covariance not only of precipitation data between each pair of sequential recording times, but also variogram values obtained from the data. The temporal change of the correlation coefficients and the covariance values suggest the following possibilities for detecting change in rainfall pattern: 1) 10-min precipitation is more useful than 1-h precipitation; 2) covariance values are more useful than correlation coefficients; 3 ) covariance of variogram values in the polar and rectangular coordinates is the best indicator for the detection on not only intensity but also directional anisotropy; and 4) covariance values of omnidirectional variogram values are also a good indicator, but probably fail to indicate some important change in rainfall pattern.
\end{abstract}

Key words : Variogram, Time, Rain, Precipitation, Pattern

\section{Introduction}

In order to prevent hazards caused by heavy rain, it is necessary to detect temporal change in rainfall patterns and to take quick measures against heavy rain. On this point of view, this paper tries to find a method indicating any change in rainfall patterns of a series of heavy rain using variograms obtained from precipitation data of the rain on 13th and 14th August, 1999, which caused a severe flood in the Kanto district, central Japan. The used data are 1-h and 10-min rain precipitations in the period from noon (12:00 JST = Japan Standard Time) on the 13th to midnight (24:00 JST) on the 14th, which are supplied through the homepage of Japan Meteorological Agency as the name of AMeDAS (Automated Meteorological Data Acquisition System). Among the data, 1-h precipitation data are the same as those used in Shoji and Kitaura (2006) and Shoji (2008), in which the rain data were analyzed statistically and geostatistically, and spatial, temporal and spatio-temporal continuities were discussed. In the Kanto district, sample stations at elevations lower than $200 \mathrm{~m}$ were selected in order to compare with the previous results. The district is about $210 \cdot 10^{2} \mathrm{~km}^{2}$ in area, and includes 81 stations. Of these, 78 and 64 stations had complete rainfall records of 1 -h and 10 -min precipitations, respectively, for the period under study (Figure 1). The spatial density of stations is, accordingly, about $1 / 270$ and 1/330 sta- tion $/ \mathrm{km}^{2}$, respectively. Thus the nearest interstation distance is about $16-18 \mathrm{~km}$ in a tetragonal grid or $18-20 \mathrm{~km}$ in a trigonal grid.

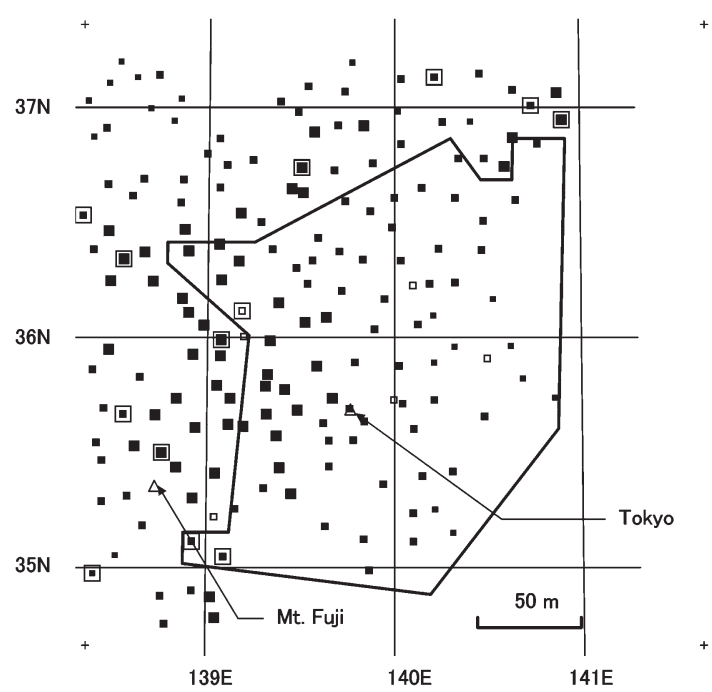

Figure 1. A map showing the spatial distribution of total precipitation values from noon (12:00 JST) on the 13th to midnight (24:00 JST) on the 14th, August 1999. The precipitation values are coded by sizes of solid squares: large $\geq 150$, middle $=150-50$, and small $\leq 50 \mathrm{~mm} / 36 \mathrm{~h}$. Small and large open squares represent unrecorded stations for $1 \mathrm{~h}$ and $10 \mathrm{~min}$, respectively. Open triangles show Mt. Fiji and Tokyo meteoric observatory. A broken line bounds the Kanto district. 
This paper deals rainfall pattern, because the purpose is to develop any method for detecting change in rainfall pattern. However, the definition of "rainfall pattern" is very difficult. Moreover, many papers use also "rain pattern" and "precipitation pattern" as terms having meaning similar to "rainfall pattern". For example, Google showed approximately 12500 , 27800 and 10400 fits for "rain pattern", "rainfall pattern" and "precipitation pattern", respectively. Many authors use any of these three terms: e.g. Wheater et al. (2000), and Morin et al. (2006) use "rainfall pattern", and Ferretti et al. (2000), and Weisse and Bois (2001) use "precipitation pattern". Some authors use two or three terms among them: e.g. Abaurrea and Asín (2005), and Amengual et al. (2008) use "rainfall pattern" and "precipitation pattern", and Geotis and Houze (1985) uses all the terms. It was impossible, unfortunately, for the present author to understand the difference among the meanings of the terms. For this reason, this paper uses "rainfall pattern" without any clear definition. Some authors use "rainfall pattern" for temporal variation of rainfall, and others for spatial distribution of rainfall. In this paper, the term means the latter sense.

Main tools to achieve the present purpose are correlation coefficient, covariance and variogram. Many authors have discussed rainfall pattern using these tools. For example, Shimada and Miyamoto (1993) apply correlation analysis to understand the temporal changes in the spatial distribution of precipitation, and they find that cross-correlation of precipitation between two observation points is available to know the characteristics of rainfall. Şen and Habib (2001) analyze monthly spatial rainfall distribution features by the spatial correlation functions and the temporal correlation functions, and show that the summer months have lower spatial correlation values than winter season, and that the average spatial correlation function decreases with distance. Durão et al. (2009) apply geostatistical methods (i.e. spatial covariance, variogram and kriging) to a data set of daily precipitation within the period 1960-1999 in Southern Portugal, and evaluate the spatial distribution of extreme precipitation events. Correlation coefficient, covariance and variogram are useful tools to analyze rainfall patterns as shown by the papers briefly reviewed above. However, they do not use correlation coefficient and covariance value of variograms, which are available to solve the present theme as shown in the following chapters. PardoIgúzquiza and Dowd (2001) use variance-covariance matrix of experimental variogram in order to assessing variogram uncertainty as a case study with rainfall data. They do not discuss, however, rainfall patterns. Shoji (2008a) evaluates similarity of two variograms with correlation coefficient between their variogram values. Shoji (2008b) uses correlation coefficient between two variograms in order to evaluate certainty of experimental variograms obtained by the partial calculations. In contrast, evaluation of dissimilarity is important in the present paper.

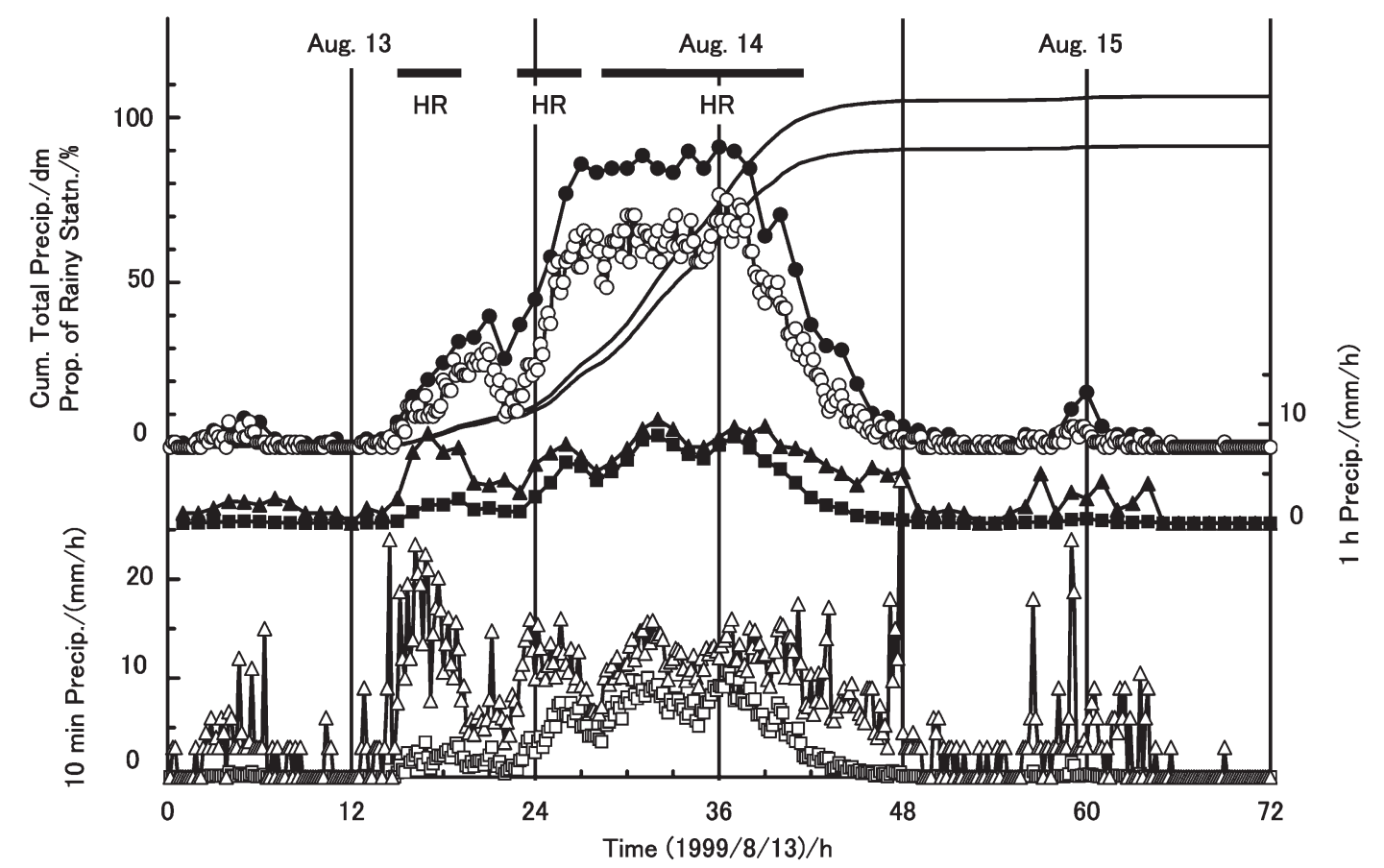

Figure 2. A diagram showing intensity of rainfall from August 13 to 15, 1999, in the Kanto district. Gradually increasing lines show temporally accumulated total precipitation values given by Equation (1) in the district: lower and upper lines correspond to 10-min and 1-h precipitations, respectively (see left upper vertical scale: the unit is $\mathrm{dm}$ ). In broken lines with any symbol, on the other hand, open and solid symbols correspond to 10-min and 1-h precipitations, respectively. Broken lines with circles show proportions of rainy stations having recorded finite values of precipitation, which is given by Equation (2) (see left upper vertical scale: the unit is \%). Broken lines with squares and triangles represent precipitation values averaged spatially in the cases including and excluding zero precipitation data given by Equations (3) and (3)', respectively (see right vertical scale and left lower scale for $1 \mathrm{~h}$ and 10-min precipitations, respectively). 


\section{Precipitation Records and Temporal Continuity of Rainfall}

In order to understand briefly the present heavy rain discussed in this paper, Figure 2 shows i) total precipitation values accumulated from 00:00 on Aug. 13 to Time $t(t=1, \cdots, 72$ for 1-h precipitation, while $00: 10, \cdots, 72: 00$ for 10-min precipitation), ii) proportions of rainy stations which recorded finite values of precipitation at Time $t$, and iii) spatially averaged values of 1-h and 10-min precipitation data at Time $t$ (10-min precipitation is given in $\mathrm{mm} / \mathrm{h}$ for comparing with 1-h precipitation), where the horizontal axis represents time from 00:00 of 13th (Time $t$ ). The total precipitation values $P_{t}$ (continuous lines in Figure 2), the proportions of rainy stations $R_{t}$ (broken lines with solid and open circles for 1-h and 10-min precipitations, respectively), and the spatially averaged values $\bar{p}_{t}$ (broken lines with squares or triangles) are given respectively by the following equations:

$$
\begin{aligned}
& P_{t}=\sum_{s} \sum_{\tau=1}^{t} p_{\tau}\left(\boldsymbol{x}_{s}\right) \\
& R_{t}=n_{\text {Pos }}^{t} / n_{\text {Pos }} \\
& \bar{p}_{t}=\sum_{s} p_{t}\left(\boldsymbol{x}_{s}\right) / n_{\text {Pos }}
\end{aligned}
$$$$
\text { (including zero precipitation values: square) }
$$

$$
\bar{p}_{t}=\sum_{s} p_{t}\left(\boldsymbol{x}_{s}\right) / n_{\text {Pos }}^{t}
$$

(excluding zero precipitation values: triangle)

where $p_{t}\left(\boldsymbol{x}_{s}\right)$ is precipitation value at Time $t$ and at Station $s$ whose position vector is $\boldsymbol{x}_{s}$, and $n_{\text {Pos }}$ and $n_{\text {Pos }}^{t}$ are respectively numbers of worked stations (78 and 64 for 1-h and 10-min precipitations, respectively), and of rainy stations at Time $t$.

In Figure 2, accumulated total precipitation values in the total area draw curves increasing gradually with time. The curve of 1-h precipitation passes through upper regions than that of 10-min precipitation, because some of stations did not record 10-min precipitation (78 and 64 for 1-h and 10-min precipitations, respectively, as stated above). The curves are steep between 26 and $38 \mathrm{~h}$. This means that the rain was heavy in the period. The proportions of rainy stations for 1-h precipitation are more than $80 \%$ in the period, and less than $50 \%$ before and after the period as shown by the broken line with solid circles in Figure 2. For 10-min precipitation, on the other hand, the proportions are $50 \%$ and $30 \%$ (the broken line with open circles), respectively. The proportions of rainy stations suggest, accordingly, that the series of rain is divided into three stages: Stage 1 (15-26 h) when the rain area became gradually wide, Stage 2 (26-38 h) when the area was the widest, and Stage 3 (38-48 h) when the area became narrow. In the case including zero precipitation data, average values of both 1 -h and 10-min precipitations are between $5-10 \mathrm{~mm} / \mathrm{h}$ on Stage 2, and less than $3 \mathrm{~mm} / \mathrm{h}$ before and after the period (Stages 1 and 3, respectively), as shown by the broken lines with solid and open squares, respectively. In the case excluding zero precipitation data, in contrast, average values are $4-10 \mathrm{~mm} / \mathrm{h}$ in 1 -h precipitation, and 5-20 $\mathrm{mm} / \mathrm{h}$ in 10 -min precipitation throughout three stages (the broken lines with solid and open triangles, respectively). These features indicate that total precipitation at every time was determined mainly by not rain intensity (i.e. precipitation value per a unit time: $\mathrm{mm} / \mathrm{h}$ here) but rain area. Especially heavy rain was recorded at the periods of 15:10-19:00, 23:00-26:50 and 28:30$41: 20$. These heavy rain periods are picked up on the basis of the following criteria: 1) spatially averaged values of 10-min precipitation excluding zero data (the broken line with open triangles) are higher than $10 \mathrm{~mm} / \mathrm{h}$ (say "intense rain" here), and 2) intense rain continues over 1 -h though a 20 min break is ignored. The heavy rain periods were scattered in three stages defined above. This implies, accordingly, that the intensity of the rain was inde-

\begin{tabular}{|c|c|c|c|c|c|c|c|}
\hline \multirow{3}{*}{$\begin{array}{l}\text { Duration of } \\
\text { Precipitation } \\
\text { Data [1] }\end{array}$} & \multicolumn{3}{|c|}{ Correlation Coefficient } & \multicolumn{3}{|c|}{ Covariance } & \multirow{3}{*}{$\begin{array}{c}\text { Mark Used in } \\
\text { Figure } 3\end{array}$} \\
\hline & \multirow{2}{*}{ Precipit. } & \multicolumn{2}{|c|}{ Variogram } & \multirow{2}{*}{ Precipit. } & \multicolumn{2}{|c|}{ Variogram } & \\
\hline & & Omnidir. & $2 \mathrm{D}[2]$ & & Omnidir. & $2 \mathrm{D}[2]$ & \\
\hline $10 \min (1)$ & Very Low & Very Low & Very Low & Very Low & High* & Very High* & Open Triangle \\
\hline $10 \min (2)$ & Very Low & Very Low & Very Low & Very Low & High & Very High & Open Diamond \\
\hline $10 \min (3)$ & Very Low & Moderate & Very Low & Low & High & Very High & Open Square \\
\hline $10 \min (6)$ & Very Low & Moderate* & Very Low & Low & High & Very High & Open Circle \\
\hline 1 hour & Low & Moderate* & Very Low & Low & High* & High* & Solid Circle \\
\hline Code in Fig. 3 & A & $\mathrm{C}$ & $E \& G$ & $\mathrm{~B}$ & $\mathrm{D}$ & $\mathrm{F} \& \mathrm{H}$ & \\
\hline
\end{tabular}
pendent of the stages.

The 1-h precipitation data discussed here have been already

Table 1. Possibility for finding change in rainfall patterns.

Asterisk (*) represents the combinations whose sequential correlation coefficients or covariance values are shown in Figure 4.

[1] The figure with a parenthesis denotes number of sequential times for averaging of precipitations, or stacking of variograms.

[2] 2D variogram includes polar and rectangular types.. 
analyzed by spatio-temporal variograms, and give the following features (Shoji, 2008a): 1) 1-h precipitation values show statistical distributions approximated by the Weibull model and somewhat less well by the normal distribution; 2) directional variograms of total precipitation shows that the continuity is the best approximately along the $\mathrm{N}-\mathrm{S}$ direction (the ranges given by directional variograms are 500 and $80 \mathrm{~km}$ along the N-S and WE directions, respectively); 3) directional variograms of 1-h precipitation values show that the direction of the best continuity is $\mathrm{W}-\mathrm{E}$ (the ranges are 50 and $100 \mathrm{~km}$ along the N-S and W-E directions, respectively); 4) the direction of the best continuity is $\mathrm{N} 0{ }^{\circ} \mathrm{W}+20^{\circ}$ in the normalized space (i.e. on a Wulff net), where geographic coordinates (horizontal plane of a unit sphere) are normalized by the spatial range ( $80 \mathrm{~km}$ given by the temporally stacked omnidirectional variogram), and time (zenith of a unit sphere) is normalized by the temporal range $(7 \mathrm{~h}$ given by the spatially stacked temporal variogram); 5) the series of heavy rainfalls had a continuity pattern elongated from west to east (the range values are $20-30 \mathrm{~km}$ and $100 \mathrm{~km}$ along N-S and W-E, respectively), and migrated from south to north with a speed of $30 \mathrm{~km} / \mathrm{h}$.

\section{Correlation and Covariance between a Sequential Time Pair}

This paper calculates many correlation coefficients and covariance values using statistical variables for finding change in rainfall pattern. The statistical variables for the calculation are easily seen in Table 1, which shows the most important result of the present work, and evaluates possibilities for finding change in rainfall patterns in the categories given by combination of kinds of statistical variables and kinds of calculated variables (i.e. correlation coefficient and covariance value). Original data of the statistical variables are $1-\mathrm{h}$ precipitation and 10 -min precipitation. 10-min precipitation data are temporally averaged in the duration of 10 (raw data themselves), 20, 30 and $60 \mathrm{~min}$ in order to avoid momentary variation. This implies that the number of kinds of precipitation data used as statistical variables is 5 (1-h precipitation and 4 kinds of 10-min precipitation). Not only the precipitation data but also variogram values of the omnidirectional, polar and rectangular types reduced from the precipitation data are also used as statistical variables. Variogram values reduced from 10-min precipitation data are temporally stacked in the duration of 10, 20, 30 and $60 \mathrm{~min}$. The number of kinds of variogram values, accordingly, are $15=5 \times 3$ (omnidirectional, polar and rectangular types), and hence the total number of kinds of statistical variables are $20(=5+15)$. Therefore, the numbers of the categories of the combination of statistical variables and the calculated variables (correlation coefficient and covariance) are 40 as shown in Table 1, where the results based on polar and rectangular variogram values are shown in the same columns because no remarkable difference was found between them.

It is very difficult to define rainfall pattern as stated in the previous chapter. In contrast, it seems to be relatively easy to define change in rainfall pattern. When two sequential times when precipitation data are recorded are $t$ and $t+1$ (exactly speaking, the recording time durations are from $t-1$ to $t$, and from $t$ to $t+1$, respectively), the correlation coefficient $r^{\mathrm{Prc}}{ }_{t^{\wedge}(t+1)}$ of precipitation values between Times $t$ and $t+1$ is given by the following equation:

$$
r_{t^{\wedge}(t+1)}^{\mathrm{Prc}}=\frac{\sum_{s}\left\{p_{t}\left(\boldsymbol{x}_{s}\right)-\bar{p}_{t}\right\}\left\{p_{t+1}\left(\boldsymbol{x}_{s}\right)-\bar{p}_{t+1}\right\}}{\sqrt{\sum_{s}\left\{p_{t}\left(\boldsymbol{x}_{s}\right)-\bar{p}_{t}\right\}^{2} \sum_{s}\left\{p_{t+1}\left(\boldsymbol{x}_{s}\right)-\bar{p}_{t+1}\right\}^{2}}}
$$

where $p_{t}\left(\boldsymbol{x}_{s}\right)$ and $p_{t+1}\left(\boldsymbol{x}_{s}\right)$ represent precipitation values at Station $s$ $\left(s=1, \cdots, n_{\text {Pos }}\right)$ whose position vector is $\boldsymbol{x}_{s}$, and $\bar{p}_{t}=\sum p_{t}\left(\boldsymbol{x}_{s}\right) / n_{\text {Pos }}$ and $\bar{p}_{t+1}=\sum p_{t+1}\left(\boldsymbol{x}_{s}\right) / n_{\text {Pos }}$ are spatially averaged precipitation values at Times $t$ and $t+1$, respectively $\left(t_{\text {Min }}\right.$ and $t_{\text {Max }}$ are 13 and 47 in the case of 1-h precipitation, and 12:10 and 47:50 in the case of 10-min precipitation, respectively). In Equation (4), Times $t$ and $t+1$ represent respectively 14 and 15 in the case of 1 -h precipitation for example, and 13:30 and 13:40 in the case of 10min precipitation, and the sequential time pairs are denoted as $14^{\wedge} 15$ and $13: 30^{\wedge} 13: 40$, respectively. Let us say $r^{\mathrm{Prc}}{ }_{t^{\wedge}(t+1)}$ "sequential correlation coefficient", and $t^{\wedge}(t+1)$ "pair of sequential times" or "sequential time pair". It will be concluded that the rain pattern scarcely changed between a pair of sequential times if the correlation coefficient was high, and that the pattern changed between a pair of sequential times if the correlation coefficient was low.

In the case that temporal change in rainfall pattern is defined by correlation coefficient of precipitation values between a pair of sequential times, it is probably concluded that rainfall pattern scarcely changes when rain becomes heavy proportionally at every station, because the calculated correlation coefficient is expected to be high. If rainfall pattern is defined by spatial distribution of normalized values, which are reduced from precipitation data by any normalization, the correlation coefficient given by Equation (4) can indicate change in rainfall pattern, because the coefficient is also normalized by variances. However, this definition is not adequate in order to find change in rainfall pattern for preventing a hazard caused by heavy rain. Rainfall pattern has to be defined not only by spatial distribution of rain precipitation but also by rain intensity. Contrary to correlation coefficient, covariance depends largely on object values themselves. This implies that covariance indicates change in rainfall pattern including temporal change of precipitation values. Covariance is expected, therefore, to be more advantageous than correlation coefficient for finding change in rainfall pattern. In this case, covariance $C^{\mathrm{Prc}}{ }_{t^{\wedge}(t+1)}$ ("sequential covariance") is 
given by the following equation:

$$
C_{t^{\wedge}(t+1)}^{\mathrm{Prc}}=\frac{\sum_{s}\left\{p_{t}\left(\boldsymbol{x}_{s}\right)-\bar{p}_{t}\right\}\left\{p_{t+1}\left(\boldsymbol{x}_{s}\right)-\bar{p}_{t+1}\right\}}{n_{\mathrm{Pos}}}
$$

The unit of the covariance is $(\mathrm{mm} / \mathrm{h})^{2}$, and hence the value is very large. In figures, consequently, temporal change of covariance is shown by the following normalized value $c^{\mathrm{Prc}_{t^{\wedge}(t+1)}}$ :

$$
c_{t^{\wedge}(t+1)}^{\mathrm{Prc}}=C_{t^{\wedge}(t+1)}^{\mathrm{Prc}} / \operatorname{MAX}\left[C_{t^{\wedge}(t+1)}^{\mathrm{Prc}}\right]
$$

where $\operatorname{MAX}\left[C^{\mathrm{Prc}_{t^{\wedge}(t+1)}}\right]$ is the maximum value among $C^{\mathrm{Prc}}{ }_{t^{\wedge}(t+1)}(t=$ $\left.t_{\text {Min }}, \cdots, t_{\text {Max }}\right)$.

Precipitation data are given as a function of spatial coordinates. This gives another problem for the definition in rainfall pattern. Generally, a rain area migrates with time (e.g. Shoji, 2008a). If it is possible to define rainfall pattern as spatial distribution of precipitation values within a rain area independently of geographic coordinates of the area, the definition seems to be more general. However, if change in rainfall pattern is defined by change of precipitation values between two sequential recording times, the definition necessarily includes migration of the rain area. In contrast, spatial variogram $\gamma_{t}(\boldsymbol{h})$ of rain precipitation values is given as a function of 2-D distance vectors $\boldsymbol{h}$ as follows:

$$
\gamma_{t}(\boldsymbol{h})=\sum\left\{p_{t}\left(\boldsymbol{x}_{s}\right)-p_{t}\left(\boldsymbol{x}_{s}+\boldsymbol{h}\right)\right\}^{2} / \varphi_{t}(\boldsymbol{h})
$$

where $\varphi_{t}(\boldsymbol{h})$ is number of pairs in calculating $\gamma_{t}(\boldsymbol{h})$. Accordingly, the value is independent of spatial coordinates. This suggests that it is possible to find change in rainfall pattern by variogram independently of migration of the rain area. For this reason, this paper takes also account of correlation coefficient $r^{\mathrm{Vrg}_{t^{\wedge}(t+1)}}$ and covariance $C^{\mathrm{Vrg}}{ }_{t^{\wedge}(t+1)}$ of variogram values between a pair of sequential times given by the following equations:

$$
\begin{aligned}
r_{t^{\wedge}(t+1)}^{\mathrm{Vrg}} & =\frac{\sum_{l}\left\{\gamma_{t}\left(\boldsymbol{h}_{l}\right)-\bar{\gamma}_{t}\right\}\left\{\gamma_{t+1}\left(\boldsymbol{h}_{l}\right)-\bar{\gamma}_{t+1}\right\}}{\sqrt{\sum_{l}\left\{\gamma_{t}\left(\boldsymbol{h}_{l}\right)-\bar{\gamma}_{t}\right\}^{2} \sum_{l}\left\{\gamma_{t+1}\left(\boldsymbol{h}_{l}\right)-\bar{\gamma}_{t+1}\right\}^{2}}} \\
C_{t^{\wedge}(t+1)}^{\mathrm{Vrg}} & =\frac{\sum_{l}\left\{\gamma_{t}\left(\boldsymbol{h}_{l}\right)-\bar{\gamma}_{t}\right\}\left\{\gamma_{t+1}\left(\boldsymbol{h}_{l}\right)-\bar{\gamma}_{t+1}\right\}}{n_{\mathrm{Lag}}} \\
c_{t^{\wedge}(t+1)}^{\mathrm{Vrg}} & =C_{t^{\wedge}(t+1)}^{\mathrm{Vrg}} / \operatorname{MAX}\left[C_{t^{\wedge}(t+1)}^{\mathrm{Vrg}}\right]
\end{aligned}
$$

where $\gamma_{t}\left(\boldsymbol{h}_{l}\right)$ and $\gamma_{t+1}\left(\boldsymbol{h}_{l}\right)$ represent variogram values at Lag $\boldsymbol{h}_{l}(l=$ $\left.1, \ldots, n_{\text {Lag }}\right), \quad \bar{\gamma}_{t}=\sum_{l} \gamma_{t}\left(\boldsymbol{h}_{l}\right) / n_{\mathrm{Lag}}$ and $\bar{\gamma}_{t+1}=\sum_{l} \gamma_{t+1}\left(\boldsymbol{h}_{l}\right) / n_{\mathrm{Lag}}$ are spatially averaged variograms at Times $t$ and $t+1$, respectively, and $\operatorname{MAX}\left[C^{\mathrm{Vrg}} t_{t^{\wedge}(t+1)}\right]$ is the maximum value among $C^{\mathrm{Vrg}_{t^{\wedge}(t+1)}}(t=$ $\left.t_{\mathrm{Min}}, \ldots, t_{\mathrm{Max}}\right)$. Variograms used for calculating the correlation coefficient and the covariance value are the polar type $\gamma(h, \theta)$ and the rectangular type $\gamma(\xi, \eta)$, which are given in polar and rectangular coordinates, respectively (a polar variogram is a set of directional variograms given at every $10^{\circ}$ here). Variograms of the omnidirectional type $\gamma(h)(h=|\boldsymbol{h}|)$ were also used for the calculation, although each set of variogram values is not connected with a distance vector $\boldsymbol{h}$. The variograms were calculated in the case including zero precipitation data with a tolerance of a $10 \mathrm{~km}$ radius circle. All sample variograms used in this paper were calculated by a program written in MS-Excel/VBA (Shoji, 2002a, b).

Data of 10 -min precipitation are more various than those of 1 -h precipitation. Correlation coefficient and covariance value of 10-min precipitation between a pair of sequential times, accordingly, vary more than those of 1 -h precipitation. In order to avoid the variation, correlation coefficient and covariance value have been also calculated for temporally averaged data of 10-min precipitation at each station. In this calculation, $p_{t}\left(\boldsymbol{x}_{s}\right)$ in Equations (4) and (5) is averaged by the following equation:

$$
p_{t}\left(\boldsymbol{x}_{s}\right)=\sum_{k} p_{t-k+1}\left(\boldsymbol{x}_{s}\right) / m_{\mathrm{Av}} \quad\left(k=1, \cdots, m_{\mathrm{Av}}\right)
$$

where $m_{\mathrm{Av}}$ is number of sequential recording times for averaging. Equations (8) and (9) give respectively correlation coefficient and covariance value for variograms using $\gamma_{t}\left(\boldsymbol{h}_{l}\right)$ stacked by the following equation:

$$
\gamma_{t}\left(\boldsymbol{h}_{l}\right)=\sum_{k} \gamma_{t-k+1}\left(\boldsymbol{h}_{l}\right) \varphi_{t-k+1}\left(\boldsymbol{h}_{l}\right) / \sum_{k} \varphi_{t-k+1}\left(\boldsymbol{h}_{l}\right) \quad\left(k=1, \cdots, m_{\mathrm{St}}\right)
$$

where $\varphi_{t-k+1}\left(\boldsymbol{h}_{l}\right)$ is number of pairs in calculating $\gamma_{t-k+1}\left(\boldsymbol{h}_{l}\right)$, and $m_{\mathrm{St}}$ is number of sequential recording times for stacking. The applied numbers of sequential times for averaging or stacking are $1,2,3$ and 6 .

\section{Temporal Change of Correlation and Covariance}

Figure 3 shows temporal change of 20 sequential correlation coefficients and 20 sequential normalized covariance values on the left and right columns, respectively (note that all lines except the bottom one shift upwards in order to avoid their overlapping in each diagram). On every diagram, each dot representing temporal change of correlation coefficients or covariance values is plotted at Time $t$, because the time is the midpoint of two sequential recording durations (from $t-1$ to $t+1$ ) represented by the time pair of $t^{\wedge}(t+1)$, and the purpose of this paper is to find the time when rain pattern changed. Note, however, that each correlation coefficient or covariance value is obtained after Time $t+1$.

Figures 3A shows sequential correlation coefficients $r^{\mathrm{Prc}}{ }_{t^{\wedge}(t+1)}$ of precipitation (Eq. 4), while Figures 3B shows sequential normalized covariance values $c^{\mathrm{Prc}_{t^{\wedge}(t+1)}}$ of precipitation (Eq. 6). On the other hand, Figures $3 \mathrm{C}, 3 \mathrm{E}$ and $3 \mathrm{G}$ show sequential correlation coefficients $r^{\mathrm{Vrg}}{ }^{\wedge}(t+1)$ of variogram values (Eq. 8) of the polar, rectangular and omnidirectional types, respective, and 

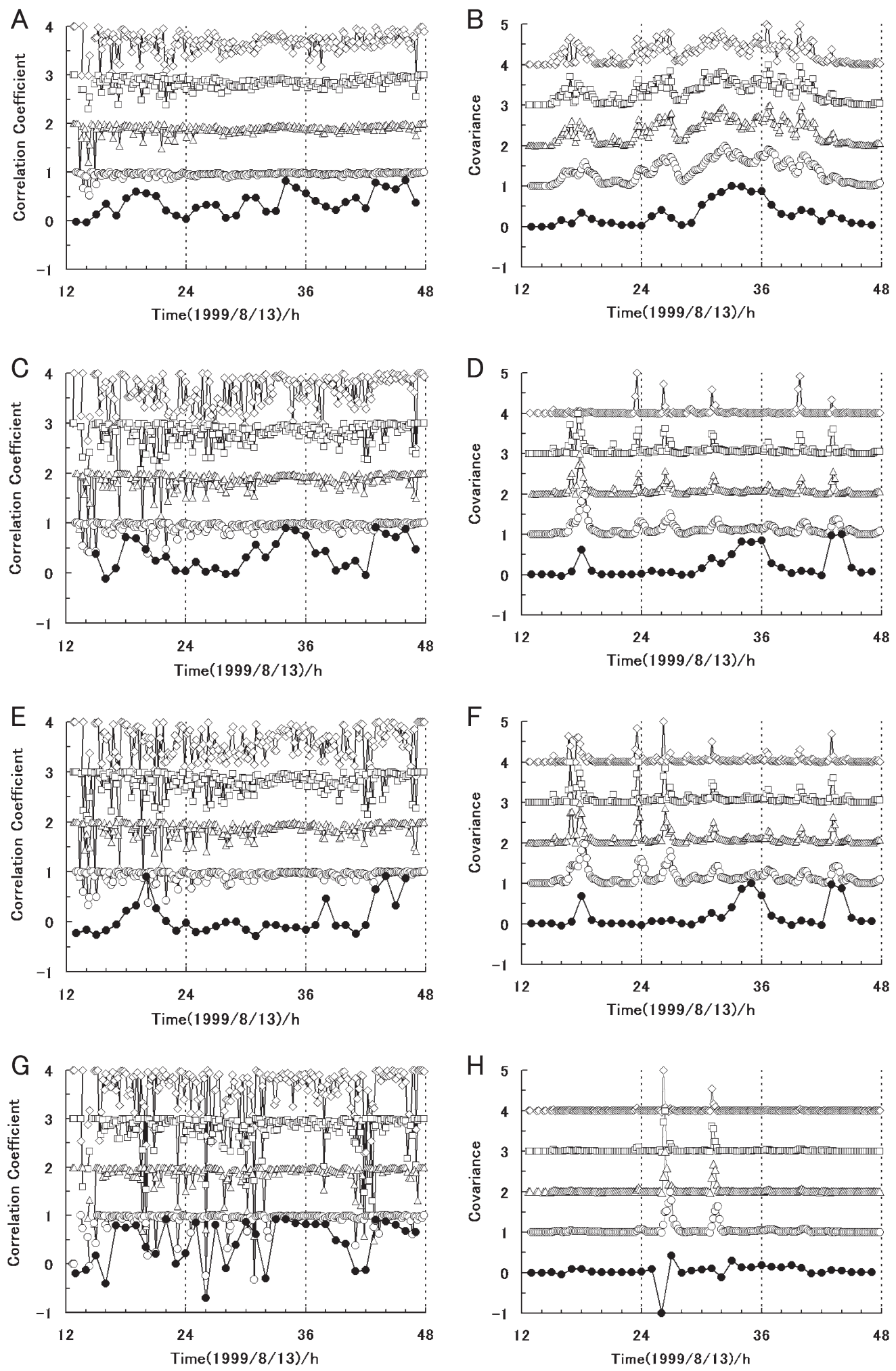

Figure 3. Sequential correlation coefficients (left; A, C, E and G) given by Equation (4) or (8), and sequential normalized covariance value (right; B, D, F and H) given by Equation (6) or (10). Statistical variables are precipitation data (Eqs. 4 and 6; A and B) and variogram values (Eqs. 8 and 10) of the polar $(\mathrm{C}$ and $\mathrm{D})$, rectangular $(\mathrm{E}$ and $\mathrm{F})$ and omnidirectional $(\mathrm{G}$ and $\mathrm{H})$ types reduced from precipitation data from the top downwards, respectively. In each figure, broken lines with open marks and solid circles represent 10-min and 1-h precipitation, respectively. The lines with open marks (triangle, diamond, square and circle) shift 3,2,1 and 0 upwards from the top downwards, respectively. The open marks represent that numbers of sequential recording times in averaging (i.e. $m_{\mathrm{Av}}$ in Eq. 11) or stacking (i.e. $m_{\mathrm{St}}$ in Eq. 12) are 1, 2, 3 and 6, respectively. Note: each dot is plotted at $t$, because the time is the midpoint of two recording time durations (from $t-1$ to $t$ and from $t$ to $t+1$ ) represented by the time pair of $t^{\wedge}(t+1)$, but the correlation coefficient $r^{\mathrm{Prc}} t^{\wedge}(t+1)$ is obtained after $t+1$. 
Figures $3 \mathrm{D}, 3 \mathrm{~F}$ and $3 \mathrm{H}$ show sequential normalized covariance values $c^{\mathrm{Vrg}_{t^{\wedge}(t+1)}}$ of variogram values (Eq. 10) of the polar, rectangular and omnidirectional types, respective. In each diagram, broken lines with open marks and solid circles represent data based on 10-min and 1-h precipitation, respectively, and the open marks of triangle, diamond, square and circle represent that numbers of sequential recording times in averaging (i.e. $m_{\mathrm{Av}}$ in Eq. 11) or stacking ( $m_{\mathrm{St}}$ in Eq. 12) are 1, 2, 3 and 6, respectively.

Figures $3 \mathrm{C}, 3 \mathrm{E}$ and $3 \mathrm{G}$ showing sequential correlation coefficients of variogram values are very similar each other. It is possible to say that especially Figure $3 \mathrm{C}$ is almost the same as Figure 3E. Figures 3D, 3F and $3 \mathrm{H}$ showing sequential covariance of variogram values are also very similar each other (Figures 3D and 3F in particular). For these reasons, let us take only the rectangular type (Figures $3 \mathrm{E}$ and $3 \mathrm{~F}$ ) as a 2-D variogram into account in the following statements.

In each diagram on the left side of Figure 3, especially Figure 3A, correlation coefficients of 10-min precipitation reach 1 with increasing number of sequential recording times for averaging $\left(m_{\mathrm{Av}}\right)$. This is because more than $80 \%(\approx 5 / 6)$ of data are overlapped if $m_{\mathrm{Av}}=6$. Correlation coefficients of 10-min precipitation in the case of $m_{\mathrm{Av}}=1$ varies from 0.5 to 1.0 , while those of 1-h precipitation are almost below 0.5 . These imply that similarity of rain patterns between a pair of sequential times is high in the case of 10-min precipitation, but low in the case of 1-h precipitation. In contrast to correlation coefficients, increasing number of sequential recording times for stacking in the vari-

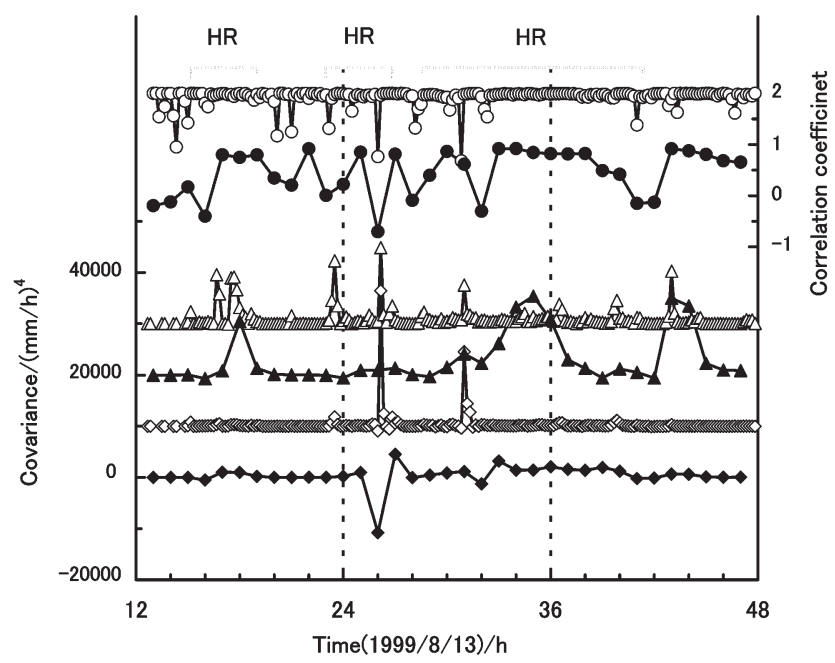

Figure 4. Selected sequential correlation coefficients (upper 2: right vertical scale) and sequential covariance values (lower 4: left vertical scale) of variogram values obtained form 10-min precipitation and 1-h precipitation data (with open and solid marks, respectively). The variogram types are omnidirectional in the top two and bottom two lines, and rectangular in the middle two lines. The top ( $m_{\mathrm{Av}}=6$ for only this) shifts 1 upwards. The lines with open triangles, solid triangles and open diamonds shift 10000, 20000 and $30000(\mathrm{~mm} / \mathrm{h})^{4}$ upwards, respectively. HR means heavy rain periods. ogram calculation (diagrams on right side of Figure 3) results that 1) temporal change of covariance value of 10-min precipitation becomes gentle, and that 2) becomes similar to that of 1-h precipitation. The second trend is completely different to the case of correlation coefficients.

Among broken lines shown in Figure 3, one of the most remarkable points is peaks appearing at the sequential time pairs of $26: 10^{\wedge} 26: 20$ and $31: 00^{\wedge} 31: 10$ on the broken line with open diamonds in Figure $3 \mathrm{H}$ (sequential covariance of omnidirectional variograms of 10 -min precipitation at $m_{\mathrm{St}}=1$ ). The peaks mean that covariance values are extremely high at the time pairs: $C^{\mathrm{Vrg}_{t^{\wedge}(t+1)}}=26000(\mathrm{~mm} / \mathrm{h})^{4}$ between $26: 10^{\wedge} 26: 20$ and 15000 between $31: 00^{\wedge} 31: 10$, but $<5000$ between other time pairs. It can be inferred, therefore, that each of the peaks indicates (i) sudden change in the rainfall pattern between the former and latter times of the time pair, and (ii) continuations of the old pattern before the former time and of the new pattern after the later time. On the other hand, many holes are observed on the broken line with open circles in Figure $3 \mathrm{G}$ (sequential correlation coefficient of omnidirectional variograms of 10-min precipitation at $m_{\mathrm{Av}}=6$ ), although they are not clear compared with the peaks stated above. The holes mean that correlation coefficients are extremely low between the time pairs: e.g. $r^{\mathrm{Vrg}}{ }_{t^{\wedge}(t+1)}=$ -0.236 between $26: 00^{\wedge} 26: 10$ and -0.318 between $30: 50^{\wedge} 31: 00$. Each of the holes also indicates, therefore, that (i) the rainfall pattern changed suddenly between the time pair, and that (ii) the old and new patterns continued before and after the time, respectively. It is highly reasonable, therefore, to consider that such peaks and holes suggest temporal changes in rainfall patterns.

Next, let us examine carefully each broken line shown in Figure 3 on the assumption that peaks and holes indicate sudden changes in rainfall patterns. Generally speaking, correlation coefficient is less advantageous than covariance as clear as compared corresponding diagrams on both sides of Figure 3 . Precipitation data especially 10-min precipitation data can scarcely indicate change in rainfall pattern. On the other hand, 1 -h precipitation data may indicate the change, though the sampling interval seems to be too long to predict rainfall hazards. In contrast to precipitation data, sequential covariance value of variogram is suggestive for finding change in rainfall pattern. In particular, 2-D variogram of 10-min precipitation seems to be an excellent indicator.

The conclusion of the examination is summarized in Table 1 which shows possibility of each of combinations among kinds of statistical properties (correlation coefficient and covariance), kinds of statistical variables (precipitation data and variogram values reduced from them) and precipitation durations (10 min and $1 \mathrm{~h}$ ) for finding change in rainfall pattern. The criteria for determining 1) "very high", 2) "high", 3) "moderate", 4) "low" and 5) "very low" are as follows: 1) each large covariance value 

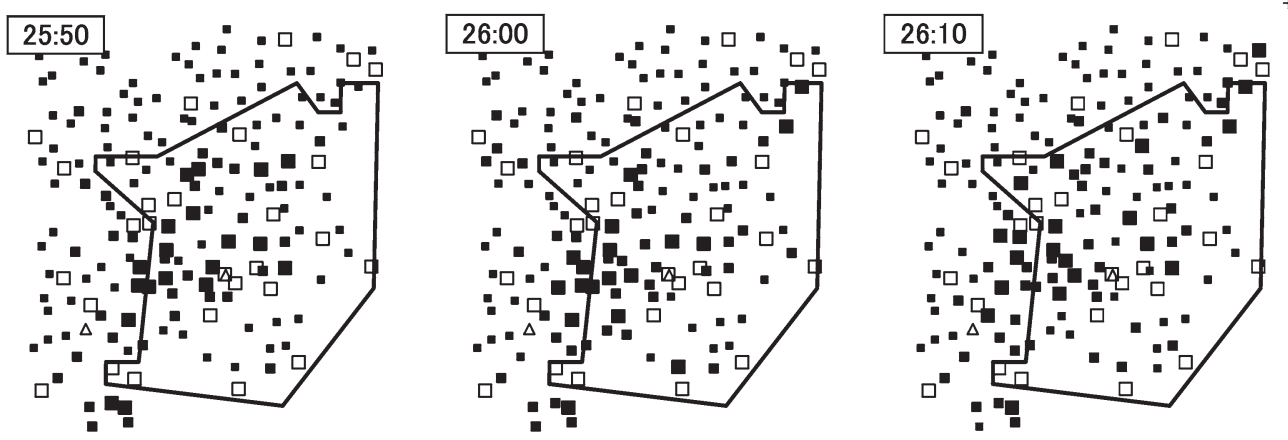

(A)
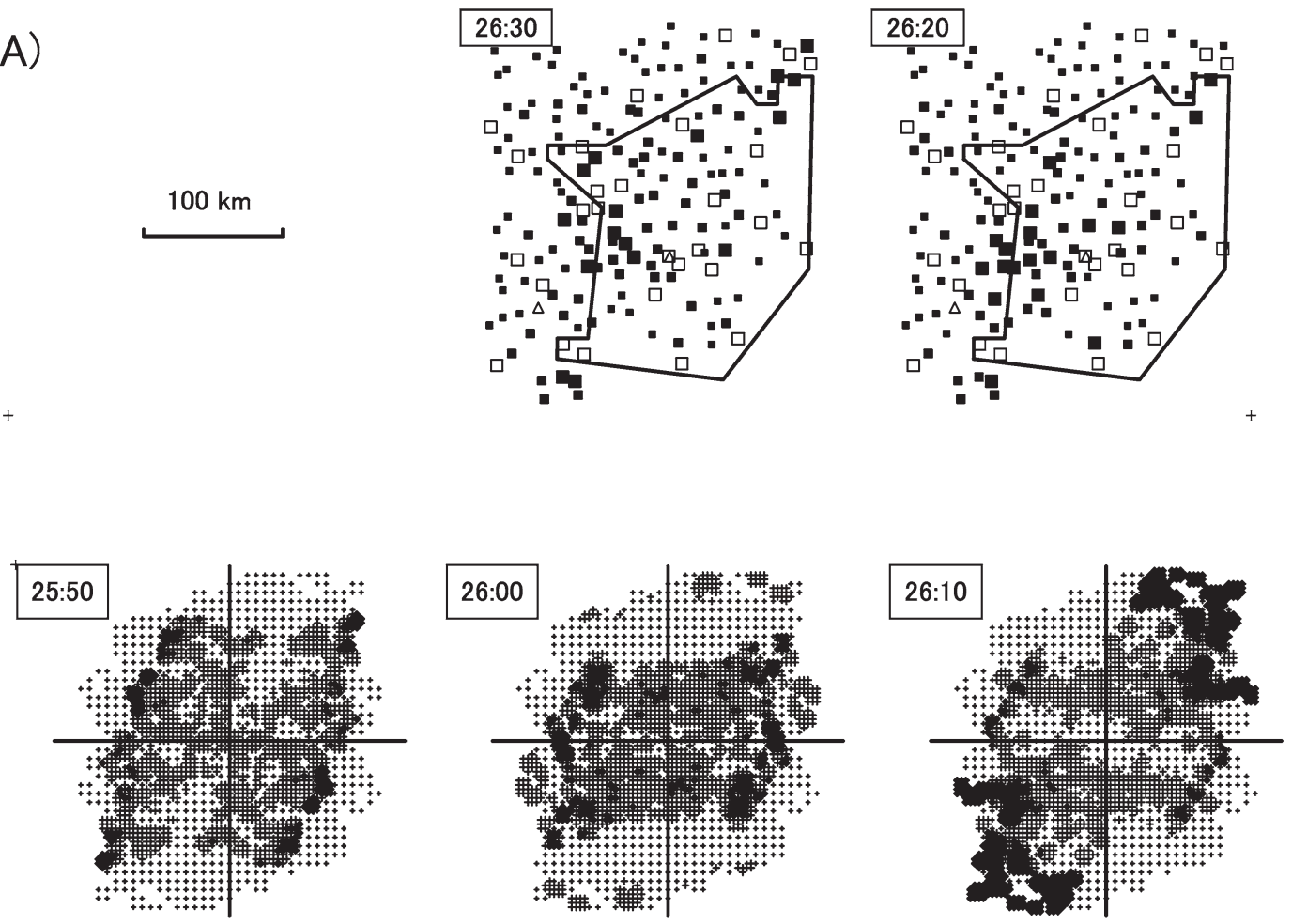

(B)
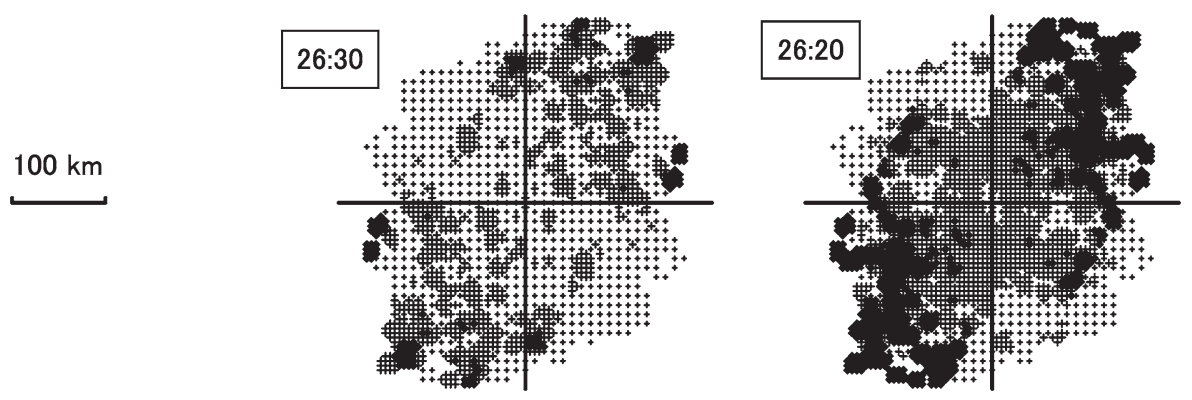

Figure 5. Maps showing the spatial distribution of 10-min precipitation (A: upper), and their rectangular variograms (B: lower) at 25:50 (exactly 25:40-25:50), 26:00, 26:10, 26:20 and 26:30. The applied tolerance for calculating the variograms is a circle whose radius is $10 \mathrm{~km}$. (A) The precipitation data are coded by sizes of solid squares: large $>10$, middle $=10-2$, and small $\leq 2 \mathrm{~mm} / \mathrm{h}$. Open squares represent unrecorded stations. A broken line is the same as Figure 1. The correlation coefficients are $0.55,0.62,0.86$ and 0.73 between 25:50 and 26:00, 26:00 and 26:10, 26:10 and 26:20, and 26:20 and 26:30, respectively, while the covariance values are $61,75,120$ and $82(\mathrm{~mm} / \mathrm{h})^{2}$, respectively. (B) The horizontal and vertical axes show W-E and N-S directions. The variogram values are coded by darkness: dark $>500$, moderate $=500-200$, and light $\leq 200(\mathrm{~mm} / \mathrm{h})^{4}$. The correlation coefficients are 0.31, 0.12, 0.99 and 0.57 between 25:50 and 26:00, 26:00 and 26:10, 26:10 and 26:20, and 26:20 and 26:30, respectively, while the covariance values are $1.1 \cdot 10^{4}, 1.6 \cdot 10^{4}, 53 \cdot 10^{4}$ and $6.4 \cdot 10^{4}(\mathrm{~mm} / \mathrm{h})^{4}$, respectively. 


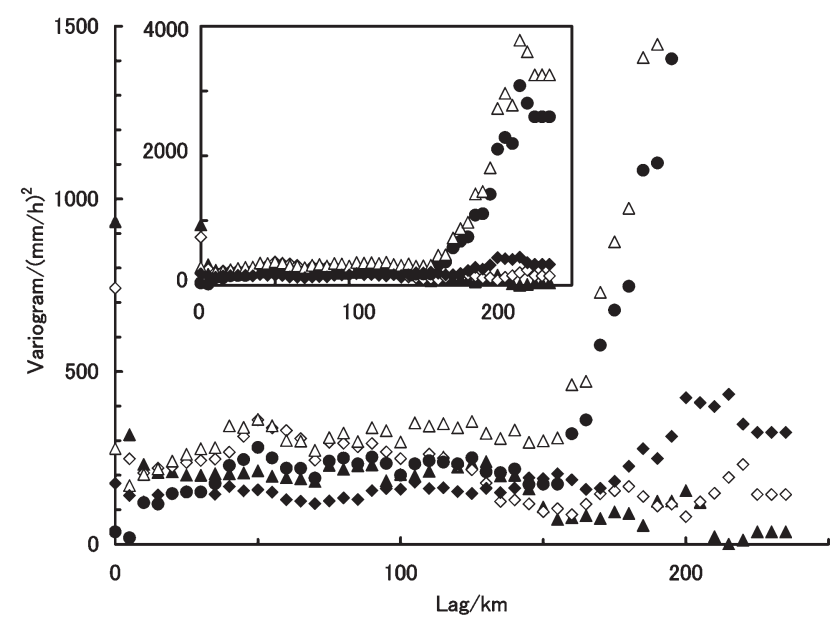

Figure 6. Omnidirectional variograms of 10-min precipitation values at 25:50, 26:00, 26:10, 26:20 and 26:30. The applied tolerance for calculating the variograms is a circle whose radius is $10 \mathrm{~km}$. The correlation coefficients are $0.83,-0.35,0.99$ and 0.94 between 25:50 and 26:00, 26:00 and 26:10, 26:10 and 26:20, and 26:20 and 26:30, respectively, while the covariance values are $1.2 \cdot 10^{4}$, $-3.3 \cdot 10^{4}, 95 \cdot 10^{4}$ and $8.9 \cdot 10^{4}(\mathrm{~mm} / \mathrm{h})^{4}$, respectively.

part is recognized as a single steep peak, 2) each large covariance value part is recognized as a wide peak or a set of peaks, 3) each small correlation coefficient part is recognized as a single depression, 4) rises or depressions are recognized, and 5) rises or depressions are scarcely recognized. As shown by asterisks in Table 1, six combinations seem to be relatively useful for finding changes in rainfall pattern. Figure 4 shows sequential correlation coefficients and sequential covariance values of the six combinations together with the heavy rain periods. Most of peaks and holes are located in the heavy rain periods. In the case of the correlation coefficient of 10-min precipitation, holes $\left(r^{\mathrm{Vrg}_{t^{\wedge}(t+1)}}<0.5\right)$ appear on the broken line with open circles (the top line in Figure 4 ) at many time pairs: 14:20^14:30, $15: 00^{\wedge} 15: 10,20: 10^{\wedge} 20: 20,21: 00^{\wedge} 21: 10,23: 10^{\wedge} 23: 20$,

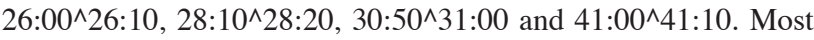
of them belong to the heavy rain period, if the time pairs belonging to Stage 1 are excluded. The holes are too many, however, to indicate important changes in rainfall pattern: most of holes probably indicate minor changes. In the case of the 2-D variograms (the broken line with open triangles passes approximately middle in Figure 4), on the other hand, peaks defined by $C^{\mathrm{Vrg}}$ $t^{\wedge}(t+1)>20 \cdot 10^{4}(\mathrm{~mm} / \mathrm{h})^{4}$ appear at six time pairs: 16:40^16:50 $\left(34 \cdot 10^{4}\right), 17: 40^{\wedge} 17: 50\left(33 \cdot 10^{4}\right), 23: 30^{\wedge} 23: 40\left(44 \cdot 10^{4}\right)$, 26:10^26:20 $\left(53 \cdot 10^{4}\right), 31: 00^{\wedge} 31: 10\left(27 \cdot 10^{4}\right)$ and $43.00^{\wedge} 43: 10$ $\left(37 \cdot 10^{4}\right)$. All of the six time pairs belong to the heavy rain periods. In contrast, the omnidirectional variograms (the second bottom line in Figure 4) has only two peaks at two time pairs: 26:10^26:20 and 31:00^21:10. The time pairs are also indicated by the $2-\mathrm{D}$ variograms. This implies that omnidirectional variograms is a good indicator for detecting change in rainfall pattern as 2-D variograms. The omnidirectional variograms seem, however, to possibly omit important changes, because the number of peaks is few.

In conclusions, 2-D variogram is the best indicator for detecting change of rainfall pattern. This conclusion is easily reduced from two important features indicated in Table 1: 1) covariance is more available than correlation coefficient, and 2) variogram of precipitation is more advantageous than precipitation itself. Correlation coefficient can hardly reflect rain intensity, because correlation coefficient is normalized by variances of

Table 2. Correlation coefficients and covariance values of 10-min precipitations and omnidirectional and rectangular variograms reduced from the precipitation data between selected time pairs.

\begin{tabular}{|c|c|c|c|c|c|c|}
\hline \multirow{3}{*}{$\begin{array}{l}\text { Sequential } \\
\text { Time Pair }\end{array}$} & \multicolumn{3}{|c|}{ Correlation Coefficient [1] } & \multicolumn{3}{|c|}{ Covariance [1] } \\
\hline & \multirow{2}{*}{ Precipit. } & \multicolumn{2}{|c|}{ Variogram } & \multirow{2}{*}{ Precipit } & \multicolumn{2}{|c|}{ Variogram } \\
\hline & & Rectang. & Omnidir. & & Rectang. & Omnidir. \\
\hline $25: 50 \wedge 26: 00$ & 0.551 & 0.313 & 0.826 & 61 & $1.1 \cdot 10^{4}$ & $1.2 \cdot 10^{4}$ \\
\hline $26: 00 ` 26: 10$ & 0.617 & 0.126 & -0.350 & 75 & $1.6 \cdot 10^{4}$ & $-3.3 \cdot 10^{4}$ \\
\hline $26: 10^{\wedge} 26: 20$ & 0.863 & 0.988 & 0.999 & 120 & $53.4 \cdot 10^{4}$ & $95.2 \cdot 10^{4}$ \\
\hline $26: 20^{\wedge} 26: 30$ & 0.733 & 0.565 & 0.939 & 82 & $6.4 \cdot 10^{4}$ & $8.9 \cdot 10^{4}$ \\
\hline $30: 40 \wedge 30: 50$ & 0.602 & 0.405 & 0.065 & 96 & $2.6 \cdot 10^{4}$ & $0.4 \cdot 10^{4}$ \\
\hline $30: 50 \wedge 31: 00$ & 0.527 & 0.144 & -0.173 & 77 & $2.7 \cdot 10^{4}$ & $-1.3 \cdot 10^{4}$ \\
\hline $31: 00 \wedge 31: 10$ & 0.604 & 0.959 & 0.997 & 120 & $27.2 \cdot 10^{4}$ & $52.4 \cdot 10^{4}$ \\
\hline $31: 10^{\wedge} 31: 20$ & 0.628 & 0.588 & 0.951 & 78 & $6.8 \cdot 10^{4}$ & $16.0 \cdot 10^{4}$ \\
\hline Unit & - & - & - & $(\mathrm{mm} / \mathrm{h})^{2}$ & $(\mathrm{~mm} / \mathrm{h})^{4}$ & $(\mathrm{~mm} / \mathrm{h})^{4}$ \\
\hline Fig. Nos. [2] & $3 \mathrm{~A}, 5 \mathrm{~A} / 7 \mathrm{~A}$ & $3 \mathrm{G}, 5 \mathrm{~B} / 7 \mathrm{~B}$ & $3 C, 6 / 8$ & $3 \mathrm{~B}, 5 \mathrm{~A} / 7 \mathrm{~A}$ & $3 \mathrm{H}, 5 \mathrm{~B} / 7 \mathrm{~B}$ & $3 \mathrm{D}, 6 / 8$ \\
\hline
\end{tabular}

[1] Bold characters represent the time pairs at each of which a hole (correlation coefficient) or a peak (covariance) appears.

[2] Figs. 3A, 3B, 3C, 3D, 3G and 3H show temporal changes of the coefficients or values, while Figs. $5 \mathrm{~A}, 5 \mathrm{~B}, 6 / 7 \mathrm{~A}, 7 \mathrm{~B}, 8$ show diagrams suggesting the correlation coefficients and covariance values at the times from $25: 50$ to $16: 30 /$ from $30: 40$ to $31: 20$. 
(A)
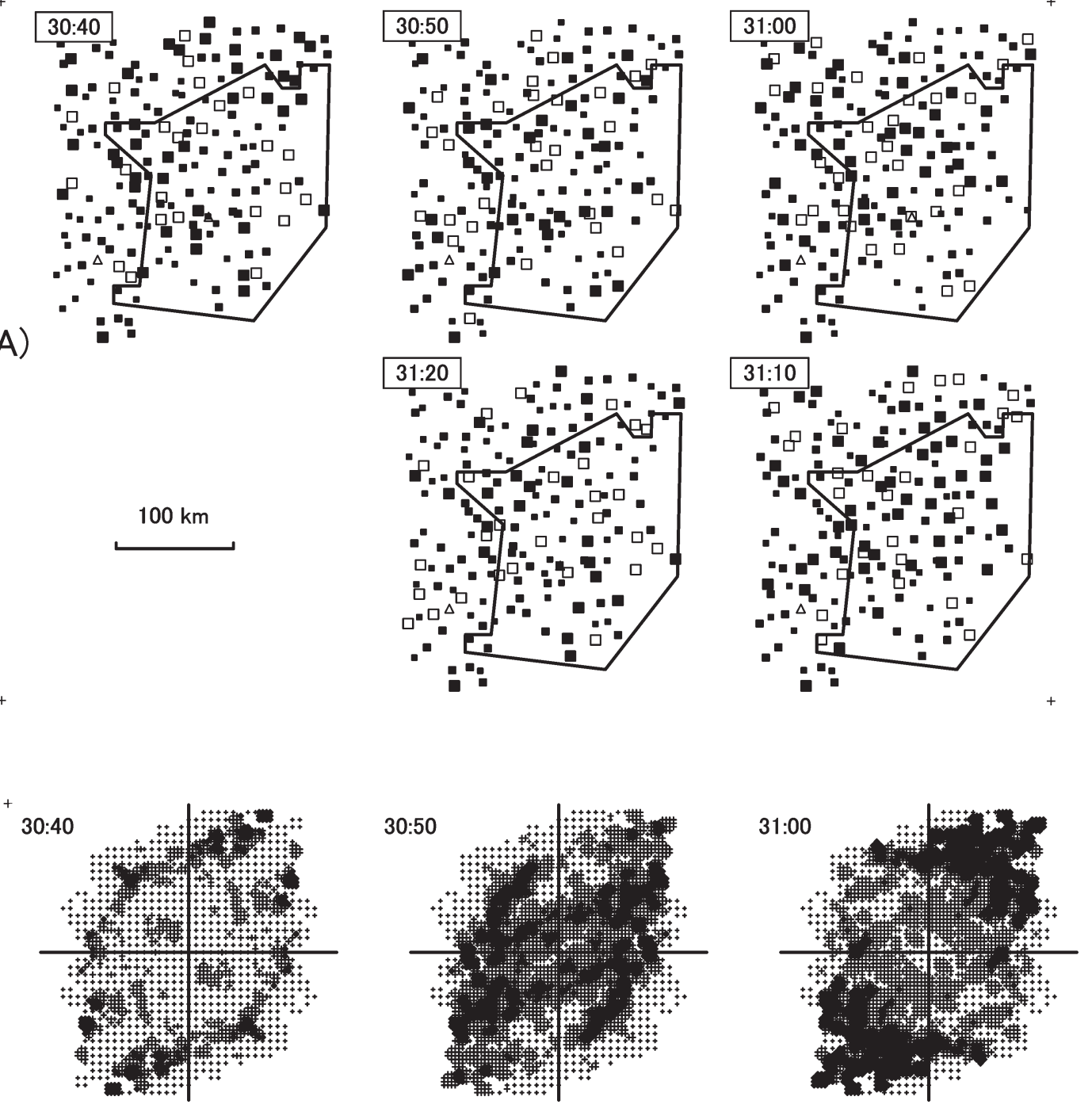

(B)
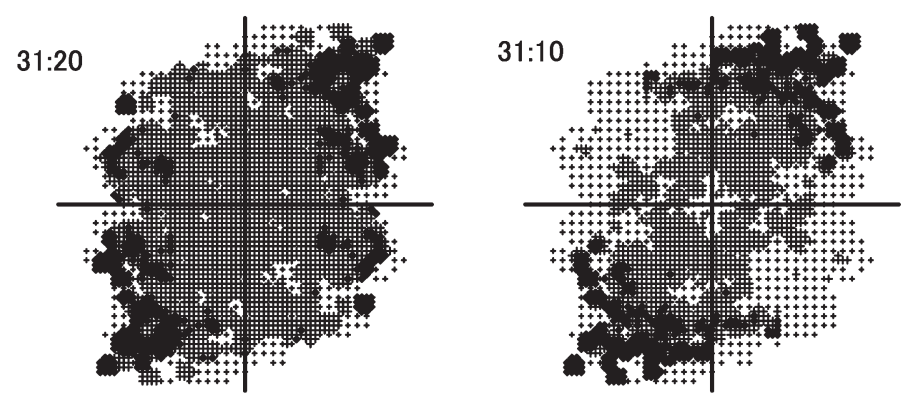

Figure 7. Maps showing the spatial distribution of 10-min precipitation (A: upper), and their rectangular variograms (B: lower) at 30:40 (exactly 30:30-30:40), 30:50, 31:00, 31:10 and 31:20. (A) The symbol size showing precipitation values, open squares and a broken line are same as Fig. 5A The correlation coefficients are 0.60, 0.53, 0.60 and 0.63 between $30: 40$ and 30:50,30:50 and 31:00, 31:00 and 31:10, and 31:10 and 31:20, respectively, while the covariance values are $96,77,120$ and $78(\mathrm{~mm} / \mathrm{h})^{2}$, respectively. (B) The axes and the darkness showing variogram values are same as Fig. 5B. The correlation coefficients are 0.41, 0.14, 0.96 and 0.59 between 30:40 and 30:50, 30:50 and 31:00, $31: 00$ and $31: 10$, and $31: 10$ and $31: 20$, respectively, while the covariance values are $2.6 \cdot 10^{4}, 2.7 \cdot 10^{4}, 27 \cdot 10^{4}$ and $6.8 \cdot 10^{4}(\mathrm{~mm} / \mathrm{h})^{4}$, respectively. 
two variables compared with covariance as stated previously. This is the main reason for the first feature. Variogram is a function of spatial continuity, and hence is considered to be able to derive more effectively spatial pattern of rainfall than precipitation itself. Moreover, the unit of variogram is $(\mathrm{mm} / \mathrm{h})^{2}$, and that of covariance of variogram is $(\mathrm{mm} / \mathrm{h})^{4}$. The square and the forth power extend large values on a diagram. These seem to be reasons for the second feature and the result that covariance of variogram is the best indicator.

\section{Change in rainfall patterns at $26: 10$ and $31: 00$}

The time pairs of $26: 10^{\wedge} 26: 20$ and $31: 00^{\wedge} 31: 10$ are common between the covariance value of the 2-D and omnidirectional variograms of 10 -min precipitation (the middle and the second bottom lines in Figure 4, respectively). Moreover, they coincide almost with the time pairs of $26: 00^{\wedge} 26: 10$ and 30:50^31:00, where remarkable holes appear on the line of the correlation coefficients of the omnidirectional variogram of 10min precipitation (the top line). The former time pair (26:10^26:20) corresponds to the boundary between Stages 1 and 2, at which the rain area became the widest, meanwhile the latter time pair corresponds to the middle of Stage 2 (Figure 2).

Figures 5 shows spatial precipitation distribution (A; upper) and rectangular variograms (B; lower) at 25:50, 26:00, 26:10, 26:20 and 26:30, when the present rain progressed from Stages 1 to 2 . Table 2 lists a correlation coefficient and a covariance value between each time pair. It is not easy to recognize the difference among the rainfall patterns based on five maps showing spatial distribution of precipitation (Figure 5A). Actually, correlation coefficients of precipitation are $0.551,0.617,0.863$ and 0.733 from $25: 50^{\wedge} 26: 10$ to $26: 20^{\wedge} 26: 30$, respectively (Table 2), and do not seem to suggest any difference indicating change in rainfall patterns. Covariance values of precipitation change gradually $65,75,120$ and $82(\mathrm{~mm} / \mathrm{h})^{2}$, respectively (Table 2 , Figure $3 \mathrm{~B}$ ), and also do not seem to suggest any difference.

The correlation coefficient of rectangular variograms between $26: 10$ and $26: 20$ (i.e. $\left.26: 10^{\wedge} 26: 20\right)$ is 0.988 (0.984 in the case of the polar variograms) (Table 2), and suggest that the variograms at 26:10 and 26:20 (Figures 5B) are very similar each other. In contrast, the covariance value is $53 \cdot 10^{4}(\mathrm{~mm} / \mathrm{h})^{4}$, and suggest that the variograms between $26: 10$ and 26:20 are different largely each other. This implies that the suggestion obtained from the correlation coefficients is quite different from that obtained from the covariance values. The difference is caused by the facts that correlation coefficient depend on only similarity of two data sets (because of normalization by variances), while covariance depend on not only the similarity but also values themselves. Accordingly, the difference suggests that variogram values given by Equation (7) increased rapidly in this time interval, because the rain intensity became strong in the whole area. It is concluded, therefore, that covariance is more advantageous than correlation coefficient for detecting change in rainfall pattern on this point. It is no wonder, however, that not only covariance but also correlation coefficient should be considered for the detection in order to get more successful suggestions.

The 2-D rectangular variograms shown in Figure 5B are clearly anisotropic. The omnidirectional variograms ignore this geometric anisotropy. Table 2 shows, however, correlation coefficients and covariance values between each sequential pair of omnidirectional variograms, since they are expected to be useful in practice because of their short calculation time. As shown in Figure 6, the values of the omnidirectional variogram at 26:00 (open diamonds) are higher than $200(\mathrm{~mm} / \mathrm{h})^{2}$ on lags shorter than $130 \mathrm{~km}$, while lower on lags longer than the distance. For this reason, the values correlate negatively $(r=-0.350)$ with those of the omnidirectional variogram at 26:10 (solid circle), which increase approximately with increasing lag. In contrast, the omnidirectional variograms at 26:10 and 26:20 are very similar to each other (solid circle and open triangle, respectively), and hence the correlation coefficient between them is very high (0.999). However, they show an extremely large covariance value $\left(95 \cdot 10^{4} \mathrm{~mm}^{4} / \mathrm{h}^{4}\right)$ because of large variogram values on long lags. This implies that the omnidirectional variograms give the same suggestion as the rectangular variograms. It is concluded, therefore, that omnidirectional variograms are also useful for detecting change in rainfall pattern.

Figures 7A, 7B and 8 show respectively precipitation distribution maps, rectangular variograms, and omnidirectional variograms at 30:40, 30:50, 31:00, 31:10 and 31:20, when the rain was the heaviest. Sequential correlation coefficients and covariance values are listed in Table 2. As similar as the case of Figure $5 \mathrm{~A}$, it is not easy to recognize differences among the rainfall patterns based on five maps showing spatial distribution of precipitation (Figure 7A). Actually, correlation coefficients of precipitation are $0.602,0.527,0.604$ and 0.628 from $30: 40^{\wedge} 30: 50$ to 31:10^31:20, respectively (Table 2), and do not seem to suggest any difference indicating change in rainfall patterns. The change of sequential covariance values of precipitation is also not remarkable: 96, 77, 120 and 78 (Table 2). The correlation coefficients of rectangular and omnidirectional variograms (Figures $7 \mathrm{~B}$ and 8 , respectively) between $31: 00$ and $31: 10$ (i.e. 31:00^31:10) are 0.959 and 0.997 , respectively (Table 2 ), and suggest that the variograms at 31:00 and 31:10 are very similar to each other independently of the variogram types (compare the right two diagrams in Figure 7B, and also compare the solid circle series and the open triangle series in Figure 8, respectively) as the case of $26: 10$ and 26:20. In contrast, the covariance value are $27 \cdot 10^{4}$ and $52 \cdot 10^{4}(\mathrm{~mm} / \mathrm{h})^{4}$, respectively, and suggest that the variograms at 31:00 and 31:10 are different largely each 


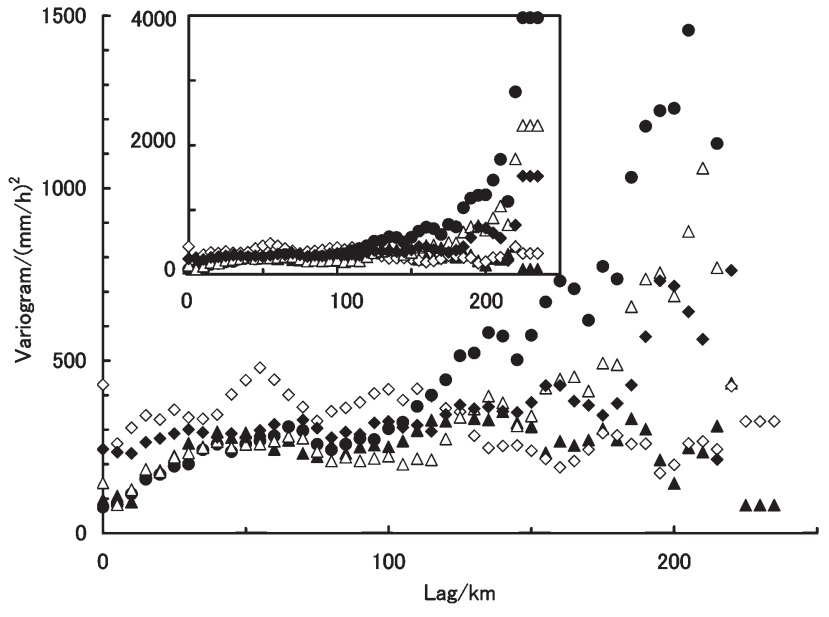

Figure 8. Omnidirectional variograms of 10-min precipitation values at 30:40, 30:50, 31:00, 31:10 and 31:20. The correlation coefficients are $0.06,-0.17,0.997$ and 0.95 between $30: 40$ and 30:50, 30:50 and $31: 00,31: 00$ and $31: 10$, and $31: 10$ and $31: 20$, respectively, while the covariance values are $0.03 \cdot 10^{4},-1.3 \cdot 10^{4}, 52 \cdot 10^{4}$ and $16 \cdot 10^{4}(\mathrm{~mm} / \mathrm{h})^{4}$, respectively.

other independently of the types. This suggestion is also the same as the case of 26:10 and 26:20. The omnidirectional variograms shown in Figure 8 show similar features to those in Figure 6, and hence give the same suggestion: omnidirectional variograms are also useful for detecting change in rainfall pattern.

Covariance values of both rectangular and omnidirectional variograms of 10 -min precipitation suggest that the pattern of the present rainfall changed at $26: 10^{\wedge} 26: 20$ and $31: 00^{\wedge} 31: 10$. The covariance values and the correlation coefficients are negative at the sequential time pairs $\left(26: 00^{\wedge} 26: 10\right.$ and $30: 50^{\wedge} 31: 00$, respectively) just before these time pairs. These negative values may play, accordingly, a foreboding role for a change in pattern rainfall. This is an attractive suggestion. In order to confirm the suggestion, however, more examination is necessary.

Finally, let us review a sequential covariance curve on the assumption that peaks of the curve indicate change in rainfall pattern. Figure 9 shows four broken lines, but the data are the same as the broken line with open triangles in Figure 4 (sequential covariance of rectangular variograms of 10-min precipitation at $\left.m_{\mathrm{St}}=1\right)$. In Figure 4, the highest peak records of the sequential covariance values are revised four times after 15:00 when the rain became stationary: $8.4 \cdot 10^{4}(\mathrm{~mm} / \mathrm{h})^{4}$ at $15: 10^{\wedge} 15: 20$, $34 \cdot 10^{4}$ at $16: 40^{\wedge} 16: 50,44 \cdot 10^{4}$ at $23: 30^{\wedge} 23: 40$ and $53 \cdot 10^{4}$ at 26:10^26:20. In Figure 9, the broken line with open circles (the top line) shows the covariance values normalized by the first peak record (the open circles are drawn just before the time at which the next peak record was observed). The covariance value shown by the broken lines with open triangles, squares and circles (the second top, second bottom and bottom lines, respectively) are normalized by the second, third and fourth peak records, respectively. If it is possible to assume that covariance values suggest a degree of change in rainfall pattern, Figure 9 indicates that the last largest change happened at 26:10, when the series of rain progressed from Stages 1 to 2 as stated previ-

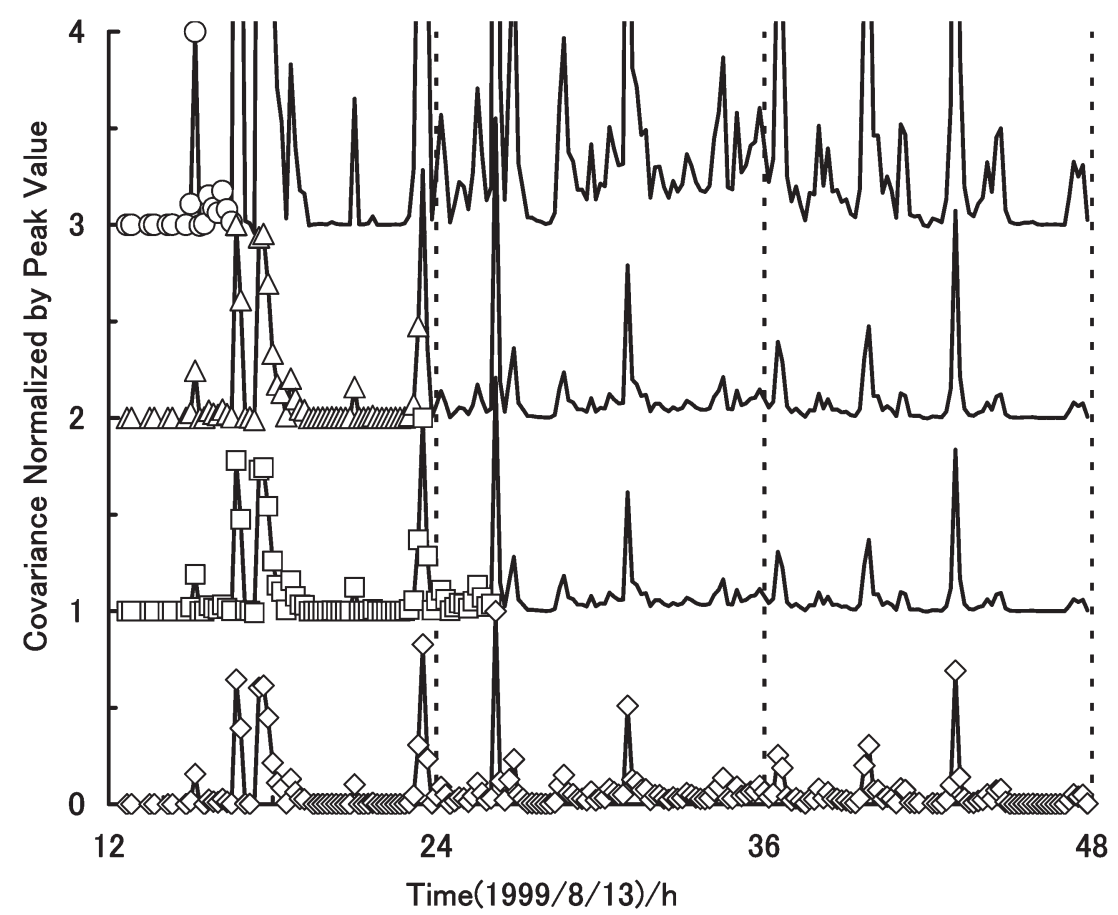

Figure 9. Sequential covariance values of rectangular variograms of 10-min precipitation. The lines with open marks shift 3 , 2, 1 and 0 upwards from the top downwards, respectively. The open marks of diamond, square, triangle and circle represent that covariance values are normalized by peak values at $15: 10^{\wedge} 15: 20,16: 40^{\wedge} 16: 50,23: 30^{\wedge} 23: 40$ and 26:10^26:20, respectively. 
ously.

This paper treats a short-term rain event. It is possible, however, to draw a figure similar to Figure 9 using long-term rainfall data such as annual precipitation. In this case, sequential covariance between sequential year pairs may indicate change in annual rainfall pattern. This implies that the method used in this paper is probably applicable for detecting climate changes in an annual scale. This is one of the next themes.

\section{Concluding Remarks}

This paper has calculated correlation coefficients and covariance values of precipitation data and variogram values obtained from the precipitation data, and discussed their availability for detecting temporal change in spatial rainfall pattern. The results suggest the following possibilities: 1) 10-min precipitation is more useful than $1-\mathrm{h}$ precipitation because of their short recording interval; 2) covariance is more useful than correlation coefficient; 3) covariance of polar and rectangular variograms is the best indicator; and 4) covariance of omnidirectional variogram values is also a good indicator for the detection, but sometimes fails to indicate important changes in rainfall pattern.

The present paper has tried to detect change in rainfall pattern, and picked up some time pairs when rainfall pattern probably changed. The change was not confirmed, however, by the meteorologists who actually experienced the present rain. In order to confirm the availability of sequential covariance of variogram of rain precipitation for detecting change in rainfall pattern, the present method should be applied simultaneously with rain observation, or at least when the meteorologists remember the rain.

The present paper dealt with a heavy rain event. It is considered, however, that the present method is available for detecting change in long-term rainfall patterns such as climate changes.

\section{Acknowledgments}

I would like to thank Dr. Chang-Jo F. Chung of the University of Ottawa and Prof. em. Liang-chi Hsu of University of Nevada, Reno, for their critical reading of the manuscript and valuable suggestions.

\section{References}

Abaurrea, J., and Asín, J. (2005) Forecasting local daily precipitation patterns in a climate change scenario. Climate Res., vol.28, no.3, pp.183-197.

Amengual, A., Diomede, T., Marsigli, C., Martín, A., Morgillo, A., Romero, R., Papetti, P., and Alonso, S. (2008) A hydrometeorological model intercomparison as a tool to quantify the forecast uncertainty in a medium size basin. Nat. Hazards
Earth System Sci., vol.8, no.4, pp.819-838.

Durão, R., Pereira1, M. J., Costa, A. C., Côrte-Real, J. M., and Soares, A. (2009) Indices of precipitation extremes in Southern Portugal - a geostatistical approach. Nat. Hazards Earth System Sci., vol.9, no.1, pp.241-250.

Ferretti, R., Paolucci, T., Zheng, W., Visconti, G., and Bonelli, P. (2000) Analyses of the precipitation pattern on the Alpine Region using different cumulus convection parameterizations. Jour. Appl. Meteorology, vol.39, no.2, pp.182-200.

Geotis, S. and Houze, R., Jr. (1985) Rain amounts near and over North Borneo during winter MONEX. Monthly Weather Rev., vol.113, no.10, pp.1824-1828.

Morin, E., Goodrich, D. C., Maddox, R. A., Gao, Xiaogang, Gupta, H. V., and Sorooshian, S. (2006) Spatial patterns in thunderstorm rainfall events and their coupling with watershed hydrological response. Advances in Water Resources, vol.29, no.6, pp.843-860.

Pardo-Igúzquiza, Eulogio, and Dowd, Peter (2001) Variancecovariance matrix of the experimental variogram: assessing variogram uncertainty. Mathematical Geology, vol.33, no.4, pp.397-419.

Șen, Z., and Habib, Z. (2001) Monthly spatial rainfall correlation functions and interpretations for Turkey. Hydrologkal Sciences-Journal-des Sciences Hydrologiques, vol.46, no.4, pp.525-535.

Shimada, T. and Miyamoto, K. (1993) Correlation analysis of rainfall: classification method of rainfall in view of sediment yield and transport. Sediment Problems: Strategies for Monitoring, Prediction and Control (Proc. Yokohama Symp., July 1993), IAHS Publ. no. 217, 39-43.

Shoji, T. (2002a) Calculation of variograms by MS-Excel/VBA. Geoinformatics, vol.13, no.1, pp.9-21. [in Japanese with English abstract]

Shoji, T. (2002b) Stereographic Projection and variogram calculation by MS-Excel/VBA. Proc. 8th Ann. Conf. IAMG (Intern. Assoc. Math. Geol.), Berlin, Germany, 15-20 Sept., 2002 (Terra Nostra, Schriften der Alfred-Wegener-Stiftung 03/2002), pp.461-464.

Shoji, T. and Kitaura, H. (2006) Statistical and geostatistical analysis of rainfall in central Japan. Computers \& Geosci., vol.32, no.1, pp.1007-1024.

Shoji, T. (2008a) Spatiotemporal continuity of sequential rain suggested by 3-D variogram. Natural Resources Research, vol.17, no.3, pp.155-165.

Shoji, T. (2008b) Reduction of accuracy and time in calculation of variogram using a part of pairs. Geoinformatics, vol.19, no.4, pp.197-208. [in Japanese with English abstract]

Weisse, A. K., and Bois, Ph. (2001) Topographic effects on statistical characteristics of heavy rainfall and mapping in the French Alps. Jour. Appl. Meteorology, vol.40, no.4, pp.720- 
740.

Wheater, H. S., Isham, V. S., Cox, D. R., Chandler, R. E. Kakou, A., Northrop, P. J., Oh, L., Onof, C. and Rodriguez-
Iturbe, I. (2000) Spatial-temporal rainfall fields: mode11ing and statistical aspects. Hydrology and Earth System Sci., vol.4, no.4, pp.581-601.

\section{要 旨}

空間ヴァリオグラムで示唆される一連の豪雨の空間パターンの時間変化

\section{: 正路徹也*}

一連の豪雨の空間的降水パターンの時間的変化を把握するために，1999 年 8 月 13 日の正午から 14 日の深夜までの 36 時間に関東地方で観測された 1 時間および 10 分間降水量のデー夕を解析した。解析では，降水量およびそれらか ら得られたヴァリオグラムの值の連続する記録時間対間での相関係数と共分散を利用した。その結果。相関係数と共 分散の時間的変化から，降水パターンの変化の把握に対して次のような結論が得られた。 1） 10 分間降水量は 1 時間 降水量より有効である．2）共分散は相関係数より有効である．3）極座標および直交座標系ヴァリオグラムは，降水 パターンの変化の把握に対して最も有効な指示因子となる．4）全方向ヴァリオグラムの共分散も有効な指示因子であ るが，重要な降水パターンの変化を見落とす可能性がある.

キーワード：ヴァリオグラム, 時間, 雨, 降水量, パターン

* 東京大学総合研究博物館 